\title{
CLINICAL SIGNIFICANCE OF PERIOPERATIVE Q-WAVE MYOCARDIAL INFARCTION: THE EMORY ANGIOPLASTY VERSUS SURGERY TRIAL
}

George T. Hodakowski, MD

Joseph M. Craver, MD

Ellis L. Jones, MD

Spencer B. King III, MD

Robert A. Guyton, MD
Objective: The primary end point of the Emory Angioplasty versus Surgery Trial was a composite of three events: death, Q-wave infarction, and a new large defect on 3-year postoperative thallium scan. This study examines the clinical significance of Q-wave infarction in the surgical cohort (194 patients) of the Emory trial. Methods: Twenty patients $(10.3 \%)$ with $Q$-wave infarctions were identified: 13 patients had inferior $Q$-wave infarctions and seven patients had anterior, lateral, septal, or posterior $Q$-wave infarctions (termed anterior $Q$-wave infarctions). Results: In the inferior $Q$-wave infarction group, postoperative cardiac catheterization (at 1 year or 3 years) in 11 patients revealed normal ejection fraction (ejection fraction $>55 \%$ ) in 10 $(91 \%)$, no wall motion abnormalities in $10(91 \%)$, and all grafts patent in 10 (91\%). In the anterior $Q$-wave infarction group, postoperative catheterizatiOn in six patients revealed normal ejection fractions in five $(83 \%)$, no wall motion abnormalities in three $(50 \%)$, and all grafts patent in three $(50 \%)$. Average peak postoperative creatine kinase MB levels were as follows: no Q-wave infarction $(n=174) 37 \pm 43 \mathrm{IU} / \mathrm{L}$, inferior $Q$-wave infarction $40 \pm$ $27 \mathrm{IU} / \mathrm{L}$, and anterior $\mathrm{Q}$-wave infarction $58 \pm 38 \mathrm{IU} / \mathrm{L}$. Mortality in the 20 patients with $Q$-wave infarctions was $5 \%(1 / 20)$ at 3 years; in patients without a $Q$-wave infarction it was $6.3 \%(11 / 174)(p=0.64)$. Of 17 patients with a $Q$-wave infarction who underwent postoperative catheterization, 11 $(65 \%)$ had a normal ejection fraction, normal wall motion, and all grafts patent with an uneventful 3-year postoperative course. Conclusions: The core laboratory screening of postoperative electrocardiograms, particularly in the case of inferior Q-wave infarctions, appears to identify a number of patients as having a $Q$-wave infarction with minimal clinical significance. $Q$-wave infarction identified in the postoperative period seems to be a weak end point with little prognostic significance and therefore not valuable for future randomized trials. (J Thorac Cardiovasc Surg 1996;112:1447-54)
Tre he clinical significance of perioperative myocardial infarctions (MIs) after coronary artery bypass graft $(\mathrm{CABG})$ operations is controversial.

From the Division of Cardiothoracic Surgery, Joseph P. Whitehead Department of Surgery, Emory University School of Medicine, Atlanta, Ga.

Read at the Seventy-sixth Annual Meeting of The American Association for Thoracic Surgery, San Diego, Calif., April 28-May 1, 1996.

Received for publication May 6, 1996; revisions requested June 3, 1996; revisions received July 29, 1996; accepted for publication August 15, 1996.

Address for reprints: Robert A. Guyton, MD, Division of Cardiothoracic Surgery, The Emory Clinic, 1365 Clifton Rd. NE, Atlanta, GA 30322.

Copyright (C) 1996 by Mosby-Year Book, Inc.

$0022-5223 / 96 \$ 5.00+0 \quad \mathbf{1 2 / 6 / 7 7 3 6 3}$
Some authors report that patients with a perioperative MI after CABG are significantly more likely to have a cardiac event, with an increased in-hospital and long-term mortality. ${ }^{1-4}$ Other investigators find that a perioperative MI is generally a benign event presaging no significant difference in outcome for these patients when compared with the prognosis of patients who have not had a perioperative MI. ${ }^{5-8}$ This variability in outcome is partly a function of the different techniques used to identify a perioperative MI. Previous studies have defined a perioperative MI as the appearance of new or enlarging $Q$ waves, elevation in the myocardial fraction of creatine kinase (CK-MB), perfusion defects on radionuclide scans, or regional wall motion abnormalities on echocardiography. ${ }^{9}$

We examined the surgical cohort of patients who 
had a perioperative Q wave MI (QMI) in the Emory Angioplasty Versus Surgery Trial (EAST) ${ }^{10}$ EAST was a prospective, randomized comparison of CABG with percutaneous transluminal coronary angioplasty (PTCA) in patients with multivessel coronary artery disease. The primary end point was a composite of three events: death, QMI, and a large ischemic defect identified on thallium scanning at 3 years. A QMI, related to the index survival procedure, was defined as the presence of a new $Q$ wave that developed during the course of the trial on a predischarge electrocardiogram. To evaluate the value of a QMI as an end point in prospective, randomized trials, we reviewed the clinical course of those patients with a perioperative QMI, as defined in the EAST.

\section{Patients and methods}

The EAST was a single-institution, prospective, randomized study comparing PTCA versus myocardial revascularization in patients with multivessel coronary artery disease. ${ }^{10}$ The primary end point was a composite of three events: death, QMI within any time during the 3-year follow-up interval, and the presence of a large ischemic defect on thallium stress studies with single-photon-emission computed tomography at 3 years. Secondary end points included ventricular function, degree of revascularization at 1 and 3 years, exercise performance, the need for subsequent revascularization procedures, the quality of life, and costs. Data were analyzed according to the intention-to-treat principle. The study was supported by the National Heart, Lung, and Blood Institute and approved by the Emory University institutional review board. Informed consent was obtained by giving a detailed presentation of the treatments, without recommending one or the other.

Patients of any age with two- or three-vessel disease who had not undergone a previous PTCA or CABG were eligible for the study. The EAST encompassed the dates of July 13, 1987, through April 15, 1990. Of the 5118 patients initially screened, 842 patients $(16.5 \%)$ were found to be eligible, and 392 patients (7.7\%) agreed to participate in the study. The patients were randomly assigned to PTCA (198 patients) and CABG (194 patients). The baseline demographic and clinical characteristics of the randomized patients did not differ significantly between the two groups. PTCA was performed by standard balloon methods with an attempt to open clinically relevant stenoses. $C A B G$ was performed with an effort to provide complete revascularization. Data were collected at baseline and every 6 months for follow-up, with all patients being followed up for the duration of the trial. A second cardiac catheterization was performed in $87 \%$ of the eligible patients at 1 year and in $76 \%$ at 3 years.

This present report comprises the 20 patients $(10.3 \%)$ in the surgical cohort of the EAST who were judged to have had a perioperative QMI. Electrocardiograms were interpreted independently by two experienced electrocar- diographers, blinded to the study data, who identified new pathologiC $\mathrm{Q}$ waves that developed during the course of the trial. In case of disagreement, a third electrocardiographer adjudicated the decision. $Q$ waves were defined by means of the Minnesota code criteria." Electrocardiograms taken in the early postoperative period, on the second or third day, were excluded from review whereas predischarge electrocardiograms in patients undergoing surgical treatment were included. Blood samples for measurement of CK and CK-MB were collected every 8 hours for 24 hours. Peak values for each patient were chosen for analysis and the data were presented as the mean \pm standard deviation.

Statistical analysis was performed with a $\chi^{2}$ test or Fisher's exact test for differences in noncontinuous variables and the paired $t$ test for continuous variables. Statistical significance was defined as $p<0.05$.

\section{Results}

In the EAST, a QMI developed after the initial procedure in 20 patients $(10.3 \%)$ of the CABG group and six patients $(3.0 \%)$ in the PTCA group. Among these 20 patients, 11 were male and nine female, with an average age of $60.1 \pm 7.9$ years. The anatomic distribution of the 20 perioperative QMIs included inferior QMIs in 13 patients (6.7\%), anteroseptal QMIs in three patients $(1.5 \%)$, lateral QMIs in three patients (1.5\%), and a posterior QMI in one patient $(0.5 \%)$. The anteroseptal, lateral, and posterior QMIs were considered as one group (anterior QMI) for the purposes of analysis.

The mean peak CK level was $902.0 \pm 639.6 \mathrm{IU} / \mathrm{L}$ $(n=167)$ in patients undergoing CABG who did not have a perioperative QMI versus $1175.8 \pm 671.5$ $\mathrm{IU} / \mathrm{L}(n=19)(p=0.08)$ in the patients diagnosed with a perioperative QMI. The CK level in inferior QMI was $1035.4 \pm 523.4 \mathrm{IU} / \mathrm{L}(n=13)$ and in anterior QMI, $1480.2 \pm 896.3 \mathrm{IU} / \mathrm{L}(n=6)(p=$ $0.187)$.

Mean peak CK-MB for patients undergoing CABG who did not have a perioperative QMI was $37.2 \pm 43.3 \mathrm{IU} / \mathrm{L}$ versus $48.3 \pm 32.3 \mathrm{IU} / \mathrm{L}$ in patients who did have a perioperative QMI $(p=0.2 \mathrm{~S})$. Mean peak CK-MB levels for patients with an inferior QMI was $39.5 \pm 27.2 \mathrm{IU} / \mathrm{L}$ and for those with an anterior QMI, $57.6 \pm 38.3 \mathrm{IU} /(p=0.21)$ (Fig. 1). Mean percent CK-MB for patients undergoing CABG who did not have a perioperative QMI was $5.9 \% \pm 4.0 \%$ versus $6.9 \% \pm 2.9 \%$ in those who did have a perioperative QMI $(p=0.29) ; 4.3 \% \pm 3.5 \%$ in inferior QMI and 5.4\% $\pm 3.9 \%$ in anterior QMI $(p=0.55)$.

In the 17 patients having a QMI who underwent follow-up cardiac catheterization at $l$ or 3 years, the 
postoperative ejection fraction was a mean of $70.5 \% \pm 12.3 \%$, with a significant difference between inferior QMI $75.2 \% \pm 9.1 \%(n=11)$ and anterior QMI 62\% $\pm 13.5 \%(n=6)(p<0.05)$. However, $91 \%$ of patients having an inferior QMI and $83 \%$ of those having an anterior QMI had a normal ejection fraction (ejection fraction $>55 \%$ ). In the 11 patients with inferior QMIs, 10 patients $(91 \%)$ had all grafts patent with no wall motion abnormalities; by contrast, among patients having anterior QMIs, three of the six patients $(50 \%)$ had all grafts patent and no wall motion abnormalities. Of these 17 patients having perioperative QMIs, 11 $(65 \%)$ had a normal ejection fraction, normal regional wall motion, and all grafts patent with an uneventful 3-year postoperative course. Of these 11 patients, nine $(81.8 \%)$ had an inferior QMI and two (33\%) had an anterior QMI.

The 20 patients with a perioperative QMI had a mean intensive care unit stay of $2.1 \pm 0.6$ days, with a mean hospital stay of $7.1 \pm 1.1$ days. Inotropic support was evaluated during the postoperative period at 12 and 24 hours. Twelve hours after the operation two patients were receiving epinephrine in dosages of 3.5 and $2.0 \mu \mathrm{g} / \mathrm{kg}$ per minute, respectively, and one patient was receiving dopamine in a dosage of $5 \mu \mathrm{g} / \mathrm{kg}$ per minute. Seventeen patients $(85 \%)$ were not receiving any inotropic support at 12 hours. At 24 hours all patients were in hemodynamically stable condition with no inotropic support.

In the EAST, in-hospital mortality included two patients $(1 \%)$ in the CABG group and two patients $(1 \%)$ in the PTCA group. During the 3 years of the study, 12 patients $(6.2 \%)$ died in the CABG arm and 14 patients $(7.1 \%)$ died in the PTCA arm $(p=0.73)$. In the CABG cohort, late death occurred in one of 20 patients $(5 \%)$ who were diagnosed with a perioperative QMI, while death occurred in 11 of the remaining 174 patients $(6.3 \%)$ who did not have a perioperative QMI ( $p=0.64)$. A cardiac cause accounted for eight of the $12(67 \%)$ deaths in the CABG group and seven of the $14(50 \%)$ deaths in the PTCA group.

Fig. 2 shows the preoperative and postoperative electrocardiograms of five patients who had perioperative inferior $\mathrm{Q}$ waves without $\mathrm{CK}-\mathrm{MB}$ elevation. Late cardiac catheterization revealed that ejection fraction and regional wall motion were within normal limits and all grafts were patent.

Fig. 3 depicts the preoperative and postoperative electrocardiograms of two patients in whom periop-

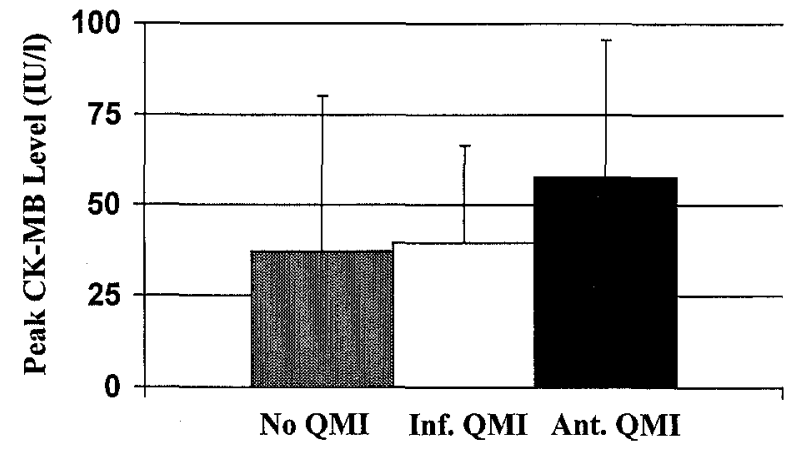

Fig. 1. Mean peak CK-MB levels in patients undergoing CABG who did not have perioperative QMI (No QMI) or who had inferior (Inf. $Q M I)(n=11)$ or anterior QMI (Ant. $Q M I)(n=6)$. Values are mean \pm standard deviation.

erative inferior $\mathrm{Q}$ waves developed associated with an elevation in the peak CK-MB. Late cardiac catheterization revealed ejection fraction and regional wall motion to be within normal limits and all grafts to be patent.

To assess the clinical impact of the combination of perioperative Q-wave development and CK-MB elevation, we divided the cohort of patients into two groups: patients with perioperative $\mathrm{Q}$ waves with and without elevation of the postoperative CK-MB above $50 \mathrm{IU} / \mathrm{L}$. Twelve patients had a CK-MB value less than $50 \mathrm{IU} / \mathrm{L}$; nine of these 12 patients had follow-up catheterization. Eight of the nine patients $(89 \%)$ had normal ejection fraction, normal wall motion, and all grafts patent. Seven patients had perioperative CK-MB elevations greater than 50 IU/L and all seven had postoperative catheterizations. Four of the seven (57\%) had a normal ejection fraction, normal regional wall motion, and all grafts patent.

\section{Discussion}

A perioperative $\mathrm{MI}$ is one of the major complications after CABG. The reported prevalence of perioperative MI ranges widely from $2 \%$ to $23 \%$, yet the exact clinical significance of a perioperative MI after CABG continues to generate controversy. ${ }^{12,13}$ Several authors report an increase in cardiac events and in-hospital and late mortality in patients undergoing CABG who have a perioperative MI. Force and associates ${ }^{1}$ found that cardiac events (defined as death, nonfatal MI, admission to the hospital for unstable angina or congestive heart failure) were significantly greater in patients with a perioperative 


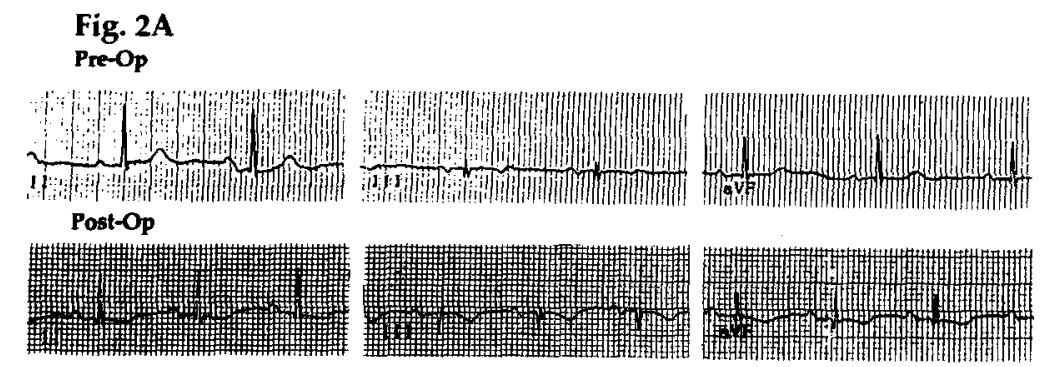

Fig. 2B
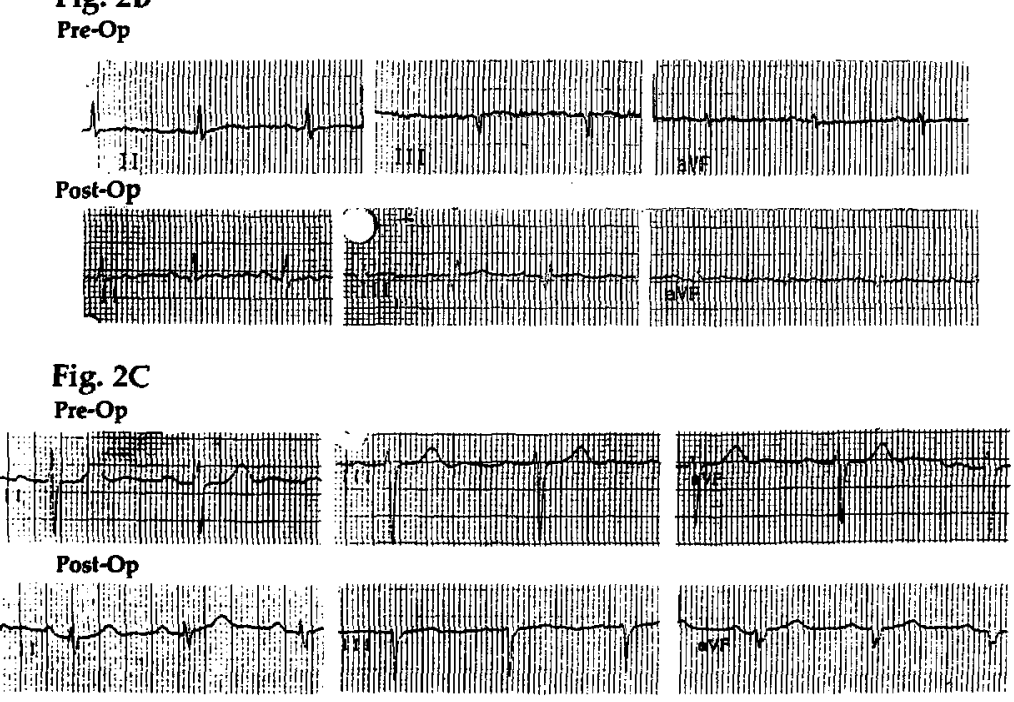

Fig. 2D

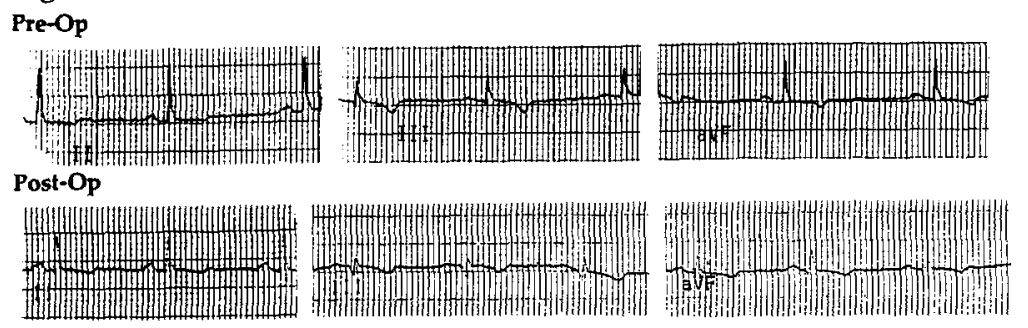

\section{Fig. 2E}

Pre-Op

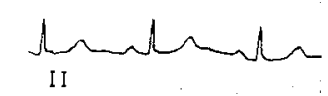

Post-Op
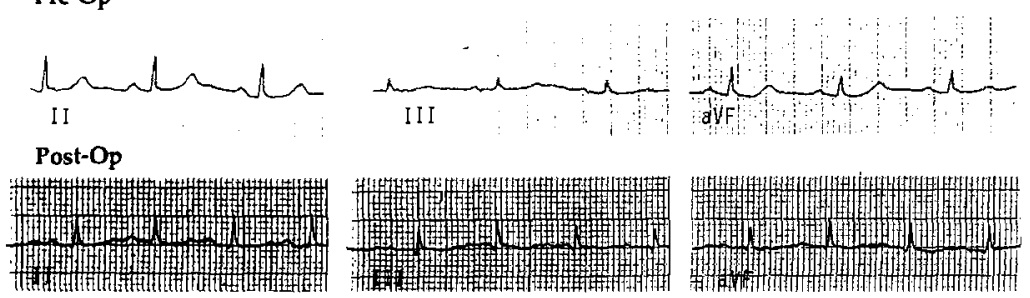

Fig. 2. Preoperative and postoperative electrocardiograms of five patients with perioperative inferior QMI, with normal associated diagnostic studies. These patients have only small electrocardiograhic changes and are unlikely to have been identified as having had a QMI by our usual clinical surveillance system. A, Peak CK-MB, 29 IU/L; ejection fraction, 81\%; wall motion by ventriculography, normal. B, Peak CK-MB, $34 \mathrm{IU} / \mathrm{L}$; ejection fraction, $82 \%$; wall motion by ventriculography, normal. C, Peak CK-MB, 18 IU/L; ejection fraction, $72 \%$; wall motion by ventriculography, normal. D, Peak CK-MB, $9 \mathrm{IU} / \mathrm{L}$; ejection fraction, 78\%; wall movement by ventriculography, normal. E, Peak CK-MB, $30 \mathrm{IU} / \mathrm{L}$; ejection fraction, $67 \%$; wall motion by ventriculography, normal. 

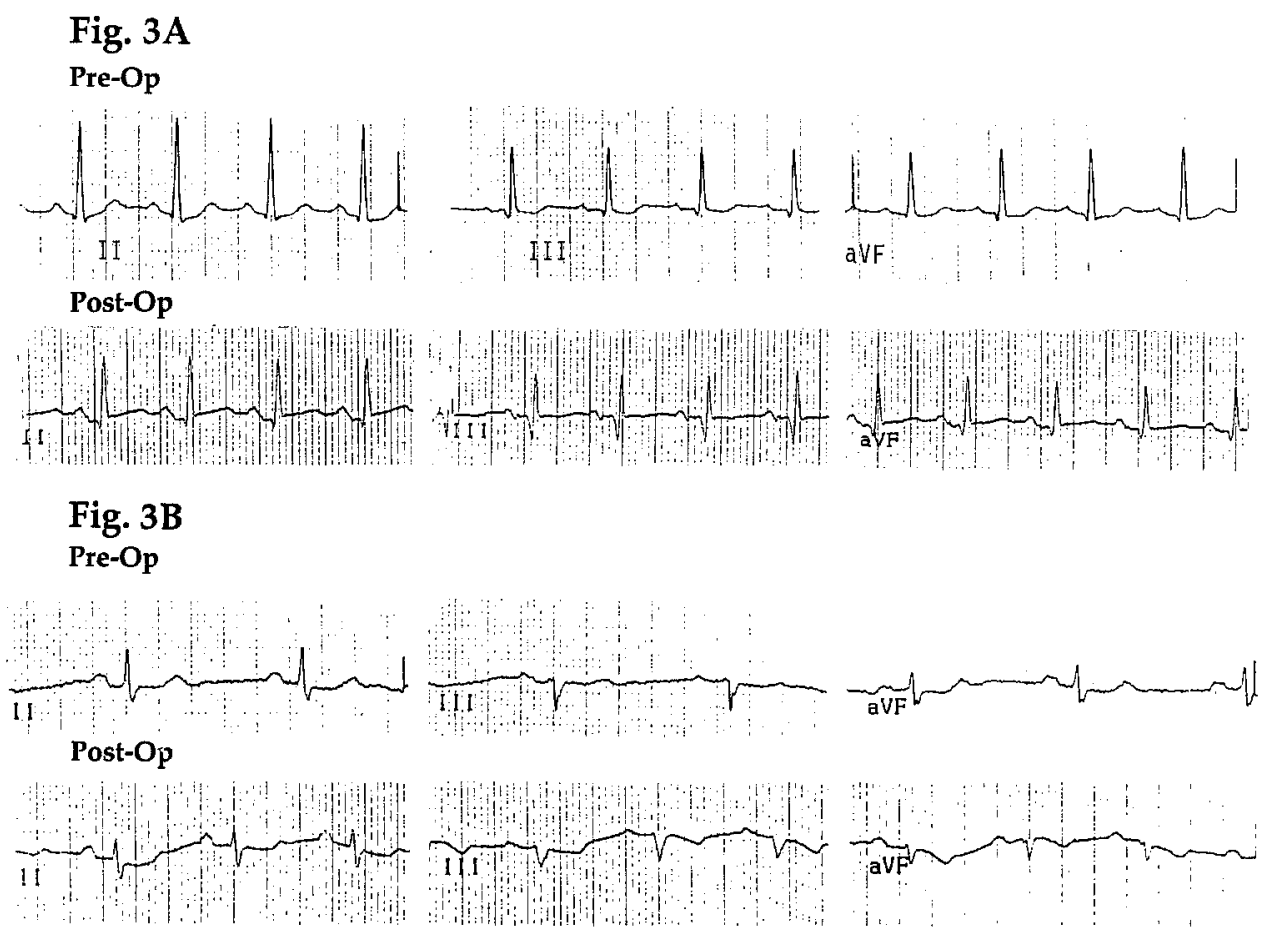

Fig. 3. Perioperative and postoperative electrocardiograms of two patients with a perioperative inferior QMI and elevated CK-MB levels, but with other diagnostic studies within the normal range. These patients have pronounced electrocardiographic changes and are likely to have been identified as having had a QMI by our usual clinical surveillance system. A, Peak CK-MB, $68 \mathrm{IU} / \mathrm{L}$; ejection fraction, $79 \%$; wall movement by ventriculography, normal. B, Peak CK-MB, $102 \mathrm{IU} / \mathrm{L}$; ejection fraction, $71 \%$; wall movement by ventriculography, normal.

MI than in patients without a perioperative MI ( $31 \%$ vs $12 \%, p<0.01$ ). In addition, multiple cardiac events were significantly more prevalent in this group of patients with a perioperative MI than in the group without a perioperative MI (19\% vs $1 \%, p<0.001)$. Another study revealed that the probability of remaining free of new cardiac complications at 2 years was $51 \%$ in the perioperative MI group compared with $96 \%$ in patients who did not have a perioperative $\mathrm{MI}^{2}$ The in-hospital mortality in patients with a perioperative MI has been noted to be $9.7 \%$ versus $1 \%$ in those patients without a perioperative MI. Hypotension and heart failure were significantly more frequent in the perioperative MI group. ${ }^{3}$ Similar results have been obtained with intermediate and long-term survival, with 3 -year survivals of $85 \%$ in patients with a perioperative MI compared with $90 \%$ in patients without a perioperative MI $(p<0.001)$ and 5 -year survivals of $76 \%$ and $90 \%(p<0.001)$ in the same groups, respectively. ${ }^{3,4}$ The risk of death for patients with a perioperative MI has been estimated to be 3.1 times greater than for comparable patients without a perioperative $\mathrm{MI}^{4}$

However, other authors maintain that a perioperative MI is generally a benign event. Operative or in-hospital mortality has been noted to be similar between patients with and without a perioperative $\mathrm{MI}^{4-6}$ In addition, long-term survival was comparable in patients who had a perioperative MI and in those who did not. ${ }^{6}$ Gray and colleagues ${ }^{7}$ reported that there was no significant difference in 5-year survival between patients with a perioperative MI and those without a perioperative MI $(96.8 \%$ vs $94.3 \%$, respectively).

This variability in survival outcomes in patients with a perioperative MI may be a function of several factors. The various studies use different diagnostic techniques (electrocardiograms, CK-MB elevations, radionuclide scans) to identify a perioperative $\mathrm{MI}$, making comparisons between studies difficult. False positive and false negative results have been noted with each of the diagnostic tests. ${ }^{3,9,14}$

Several authors have noted the resolution or 
disappearance of perioperative $Q$ waves. ${ }^{15,16}$ This finding may be due to scar contracture or hypertrophy of adjacent myocardium during healing, the recovery of stunned myocardium, or the resolution of peri-MI edema fluid. ${ }^{15,17,18}$ In addition, revascularization of ischemic myocardium may "unmask" a preexisting MI in the vectorially opposite myocardium. For example, the appearance of inferior $\mathrm{Q}$ waves, which previously had been canceled out by ischemic anterior myocardium, become "unmasked" with the revascularization of the anterior myocardium. ${ }^{14}$ Bulkley and Hutchins ${ }^{19}$ indicated the low sensitivity of electrocardiograms to diagnose a perioperative MI. Of 13 patients with myocardial necrosis on autopsy 1 month after CABG, only three patients $(23 \%)$ had had new $Q$ waves on a postoperative electrocardiogram.

The CK-MB level is frequently used to detect an acute MI. The level of CK-MB rises within the serum at 6 to 10 hours, with maximal levels reached between 14 and 36 hours. ${ }^{20}$ Both ventricular and atrial myocardium contain CK-MB isoenzyme, and cannulation of the atrium may result in an elevation of CK-MB. ${ }^{21}$ False elevations of CK-MB levels have also been observed with direct-current defibrillation, renal failure, hypothyroidism, and mesenteric infarction producing bowel necrosis. ${ }^{9,22,23}$

A perfusion defect on a radionuclide scan such as technetium $99 \mathrm{~m}$ pyrophosphate is indicative of an acute MI. The mechanism of action of ${ }^{99 \mathrm{~m}}$ Tc pyrophosphate is by binding to mitochondrial $\mathrm{CA}^{++}$ within a damaged myocyte. ${ }^{24}$ As the cell becomes irreversibly damaged, intracellular $\mathrm{Ca}^{++}$increases with a resultant increase in the binding of ${ }^{99 \mathrm{~m}} \mathrm{Tc}$ pyrophosphate. However, an increased uptake of ${ }^{99}$ Tc pyrophosphate has also been observed with a remote MI, cardioversion, and a ventricular aneurysm. ${ }^{9}$ Nonetheless, improved diagnostic accuracy can be achieved by the correlation of multiple diagnostic tests for myocardial necrosis. ${ }^{2}$

The EAST electrocardiography committee identified a perioperative QMI in $10.3 \%(20 / 194)$ of the patients in the CABG group, compared with a QMI rate of $3 \%(6 / 198)$ of the patients in the PTCA group $(p=0.004)$. This perioperative MI rate is approximately five times the infarct rate of first-time CABG previously reported from Emory University during a similar time period. ${ }^{25}$ This discrepancy is related to the fact that the core laboratory analysis of perioperative electrocardiograms is much more sensitive in the diagnosis of QMI than our usual clinical surveillance system. Fig. 2 illustrates five patients identified as having QMIs in EAST with only small electrocardiographic changes. All five patients had unremarkable perioperative CK-MB levels and normal ejection fractions and wall motion at late catheterization. These patients are examples of patients identified as having a QMI in EAST who were not likely to be identified as having a QMI by our normal surveillance system. Fig. 3, on the other hand, depicts two patients very likely to be identified as having a QMI by our usual surveillance system.

There was no significant difference in the mean $\mathrm{CK}, \mathrm{CK}-\mathrm{MB}$, and percent CK-MB between patients in whom perioperative QMI was diagnosed and those patients without a perioperative QMI. Although each of these parameters was greater in the patients having an anterior QMI than in those having an inferior QMI, the difference did not achieve statistical significance.

The ejection fraction calculated by ventriculography on cardiac catheterization was $69 \%$ in both the CABG and PTCA groups in EAST. This was not different from the ejection fraction of $71 \%$ in the 17 patients with a perioperative QMI. Of note, there was a significant difference in the ejection fractions between the patients with inferior QMI and anterior QMI, 75\% versus $62 \%(p<0.05)$, respectively. Further analysis of the cardiac catheterization data at either 1 or 3 years revealed that $91 \%(10 / 11)$ of the patients having inferior QMI and 50\% (3/6) of those having anterior QMI had all grafts patent and no wall motion abnormalities. Although the patients having inferior QMI appeared to have a better clinical outcome than those having anterior QMI, the sample sizes were too small for meaningful comparison.

All patients had been weaned from inotropic agents 24 hours after the operation. In-hospital mortality occurred in two patients $(1 \%)$ in the CABG group, neither of whom was in the perioperative QMI surgical cohort. During the 3-year study interval, death occurred in $5 \%(1 / 20)$ of the CABG group with a perioperative QMI, 6.3\% (11/ 174) of the patients in the CABG group without a perioperative QMI, and 7.1\% (14/198) in the PTCA group $(p=0.25)$. There was no detectable difference in clinical outcome in the EAST between patients identified as having a QMI after CABG and the outcome of the other patients in the trial.

The best suggestion for diagnosing clinically relevant myocardial necrosis in the perioperative interval may be the combination of perioperative $Q$ waves on the electrocardiogram and the elevation of 
perioperative CK-MB levels. When this cohort of patients was analyzed by means of this combination of criteria, 12 patients had $Q$ waves without CK-MB elevation and seven patients had $Q$ waves with CK-MB elevation. Eighty-nine percent of the patients without CK-MB elevation had normal findings on postoperative catheterization, whereas only $57 \%$ of the patients with a combination of CK-MB elevation and perioperative $\mathrm{Q}$ waves had normal findings on catheterization ( $p=0.262$ ). Inasmuch as a QMI identified by electrocardiographic criteria alone in the postoperative period seems to be a weak end point without prognostic importance, perhaps the combination of perioperative Q-wave development and CK-MB elevation will more accurately identify clinically significant perioperative myocardial necrosis.

\section{REFERENCES}

1. Force T, Hibberd P, Weeks G, et al. Perioperative myocardial infarction after coronary artery bypass surgery: clinical significance and approach to risk stratification. Circulation 1990;82:903-12.

2. Val PG, Pelletier LC, Hernandez MG, et al. Diagnostic criteria and prognosis of perioperative myocardial infarction following coronary bypass. J Thorac Cardiovasc Surg 1983; 86:878-86.

3. Chairman BR, Alderman EL, Sheffield LT, et al, and the participating CASS medical centers. Use of survival analysis to determine the clinical significance of new $Q$ waves after coronary bypass surgery. Circulation 1983;67:302-9.

4. Namay DL, Hammermeister KE, Zia MS, DeRouen TA, Dodge HT, Namay K. Effect of perioperative myocardial infarction on late survival in patients undergoing coronary artery bypass surgery. Circulation 1982;65:1066-71.

5. Burton JR, FitzGibbon GM, Keon WJ, Leach AJ. Perioperative myocardial infarction complicating coronary bypass: clinical and angiographic correlations and prognosis. J Thorac Cardiovasc Surg 1981;82:758-64.

6. Espinoza A, Lipski J, Litwak R, Donoso E, Dack S. New Q waves after coronary artery bypass surgery for angina pectoris. Am J Cardiol 1974;33:221-4.

7. Gray RJ, Matloff JM, Conklin CM, et al. Perioperative myocardial infarction: late clinical course after coronary artery bypass surgery. Circulation 1982;66:1185-9.

8. Codd JE, Wiens RD, Kaiser GC, et al. Late sequelae of perioperative myocardial infarction. Ann Thorac Surg 1978; 26:208-13.

9. Jain U. Myocardial infarction during coronary artery bypass surgery. J Cardiothorac Vasc Anesth 1992;6:612-23.

10. King SB III, Lembo NJ, Weintraub WS, et al. A randomized trial comparing coronary angioplasty with coronary bypass surgery. N Engl J Med 1994;331:1044-50.

11. Prineas RJ, Blackburn H, Crow RS. The Minnesota code manual of electrocardiographic findings: standards and procedures for measurement and classification. Boston: WrightPSG, 1982:203.

12. Burns RJ, Gladstone PJ, Tremblay PC. Myocardial infarction determined by technetium-99m pyrophosphate single-photon tomography complicating elective coronary artery bypass grafting for angina pectoris. Am J Cardiol 1989;63:1429-34.

13. Righetti A, O'Rourke RA, Schelbert H, et al. Usefulness of preoperative and postoperative TC-(m-[Sn])-pyrophosphate in patients with ischemic and valvular heart disease. Am J Cardiol 1977;39:43-9.

14. Bassan MM, Oatfield R, Hoffman I, Matloff J, Swan HJC. New $Q$ waves after aortocoronary bypass surgery: unmasking of an old infarction. N Engl J Med 1974;290:349-53.

15. Chuang MY, Spodick DH. Electrocardiographic Q wave inconstancy in inferior wall myocardial infarction. Am J Cardiol 1990;66:1144-6.

16. Kennedy FB, Ticzon AR, Duffy FC, Raymundo LR, Giacobine JW. Disappearance of electrocardiographic pattern of inferior wall myocardial infarction after aorta-coronary bypass surgery. J Thorac Cardiovasc Surg 1977;74:586-93.

17. Aronow WS, Starling L, Etienne F, D'Alba P, Edwards M, Lee NH, Parungay RF. Unrecognized Q-wave myocardial infarction in patients older than 64 years old. Am J Cardio1 1985:55:483-9.

18. Albert DE, Califf RM, LeCocq DA, McKinnis RA, Ideker RE, Wagner GS. Comparative rates of resolution of QRS changes after operative and nonoperative acute myocardial infarcts. Am J Cardiol 1983;51:378-81.

19. Bulkley BH, Hutchins GM. Myocardial consequences of coronary artery bypass graft surgery: the paradox of necrosis in areas of revascularization. Circulation 1977;56:906-13.

20. Roberts R. Enzymatic diagnosis of acute myocardial infarction. Chest 1988;93:3s-6s.

21. Graeber GM, Shawl FA, Head HD, et al. Changes in serum creatine kinase and lactate dehydrogenase caused by acute perioperative myocardial infarction and by transatrial cardiac surgical procedures. J Thorac Cardiovasc Surg 1986;92:63-72.

22. O'Neill PG, Faitelson L, Taylor A, Puleo P, Roberts R, Pacifico A. Time course of creatine kinase release after termination of sustained ventricular dysrhythmias. Am Heart J 1991;122:709-14.

23. Graeber GM, Clagett GP, Wolf RE, Cafferty PJ, Harmon JW, Rich NM. Alterations in serum creatine kinase and lactate dehydrogenase: association with abdominal aortic surgery, myocardial infarction and bowel necrosis. Chest 1990;97:521-7.

24. Buja LM, Tofe A, Kulkarni PV, Mukherjee A, Parkey RW, Francis MD. Sites and mechanisms of localization of technetium-99m phosphorous radiopharmaceuticals in acute myocardial infarcts and other tissues. J Clin Invest 1977;60:72440.

25. Jones EL, Weintraub WS, Craver JM, Guyton RA, Cohen $\mathrm{CL}$. Coronary bypass surgery: Is the operation different today? J Thorac Cardiovase Surg 1991;101:108-15.

\section{Discussion}

Dr. Bruce W. Lytle (Cleveland, Ohio). One of the advantages of a randomized trial is that the patients are studied longitudinally and a lot of other information becomes available. What you and your colleagues have shown is that an isolated electrocardiographic finding of a $Q$ wave in the early postoperative period does not necessarily correlate with enzyme elevation, subsequent clinical outcome, or wall motion abnormalities. Thus the term $Q M I$, at least for this group of patients, is a misnomer. 
There are $\mathrm{Q}$ waves and there are MIs, but $\mathrm{Q}$ waves do not necessarily identify the MIs. My only question is this: If we are not going to use $\mathrm{Q}$ waves to identify perioperative MIs, then what are we going to use? You do have a group of patients that were documented to have wall motion abnormalities at late cardiac catheterization. Can you identify anything in the perioperative tests that predicted the occurrence of a late wall motion abnormality, for example, enzyme elevation combined with a $Q$ wave, perhaps?

Dr. Hodakowski. That is a very good question, and indeed that is a problem in identifying perioperative QMIs. These ventriculograms were performed 1 and 3 years after the study. The way we at Emory identify a perioperative QMI is by having not only electrocardiographic criteria but also the elevation of CK. Wall motion is a very specific way of identifying MIs. Ninety-one percent of the patients in the inferior QMI group had normal wall motion. So one or two patients of the 20 patients indeed had abnormal wall motion. That is a good point. But not many in this group of patients had abnor- mal wall motion. Generally, approximately $50 \%$ of patients having Q-wave changes and elevated CK-MB levels might have abnormal wall motion as well as occluded grafts.

Dr. Lytle. I realize that you were specifically evaluating the surgical group, but six patients having PTCA had new Q waves. Was there a similar discordance between $\mathrm{Q}$ waves and other findings for that group, or don't you know?

Dr. Hodakowski. We do not have that information. I'm sorry.

Dr. Robert B. Wallace (Washington, D.C.). In view of these data and the attempt to restrict the ineffective use of resources, do you continue in your practice at Emory to routinely monitor CK levels and electrocardiograms in the postoperative period?

Dr. Hodakowski. Generally we get a postoperative electrocardiogram, but the CKs are used on a per-patient basis. If we are concerned that the patient may have had problems or is hemodynamically unstable or gives other indications of having myocardial damage, then we will measure CK-MB levels, but it is not a routine.

\section{Bound volumes available to subscribers}

Bound volumes of The Journal of Thoracic and Cardiovascular Surgery are available to subscribers (only) for the 1997 issues from the Publisher, at a cost of $\$ 110.50$ for domestic, $\$ 139.64$ for Canadian, and $\$ 130.50$ for international subscribers for Vol. 113 (January-June) and Vol. 114 (July-December). Shipping charges are included. Each bound volume contains a subject and author index and all advertising is removed. Copies are shipped within 60 days after publication of the last issue of the volume. The binding is durable buckram with the Journal name, volume number, and year stamped in gold on the spine. Payment must accompany all orders. Contact Mosby-Year Book, Inc., Subscription Services, 11830 Westline Industrial Drive, St. Louis, Missouri 63146-3318, USA; phone 800-453-4351 or 314-453-4351.

Subscriptions must be in force to qualify. Bound volumes are not available in place of a regular Journal subscription. 